ميزان شيوع استافيلوكوكوس اورئوس با كاهش حساسيت نسبت به ونكومايسين

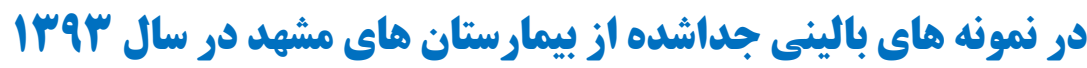

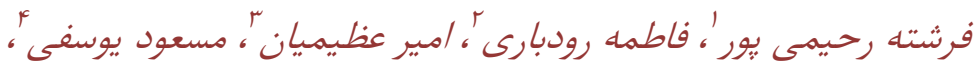

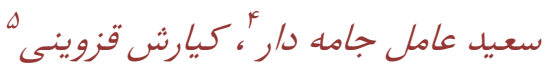

'كارشناس ارشد ميكروبيولوزى، گروه زيست شناسى - سلولى و مولكولى، دانشكده علوم پايه، دانشعاه مازندران، بابلسر، ايران

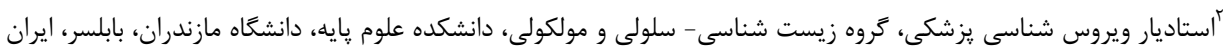

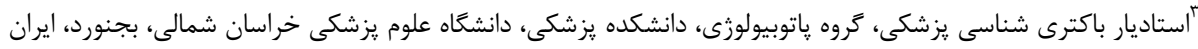

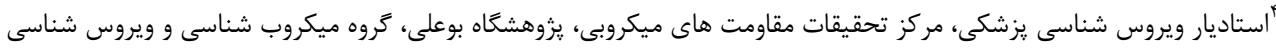

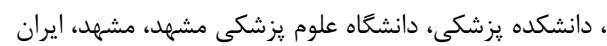

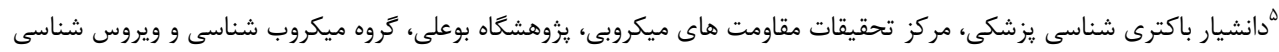

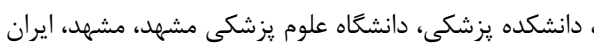

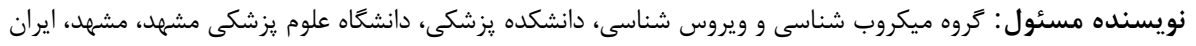

بست الكترونيك: GhazviniK@ mums.ac.ir

010

زمينه و اهداف: استافيلوكوكوس /ورئوس يكى /ز عوامل مهمر عفونت هاى بيمارستانى مى باشد. اخيرا افزايش

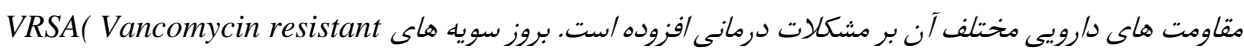
) staphylococcus aureus)

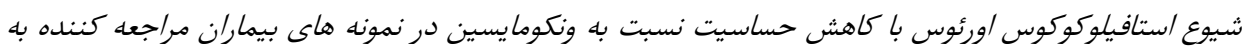

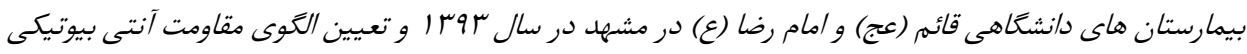
آنها بود.

مواد و روش كار: در /ين مطالعه توصيفى- مقطعى در طى V ماه، V IV سويه /ستافيلوكوكوس /ورئوس /ز نمونه

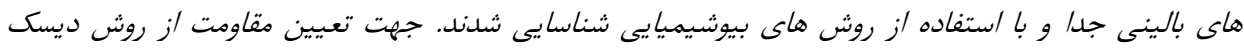

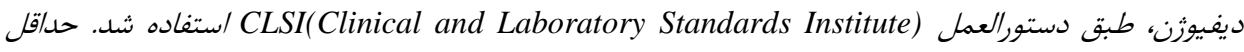

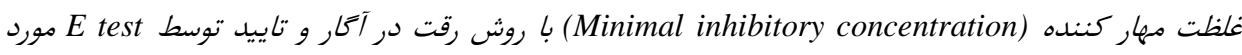
بررسى قراركرفت.

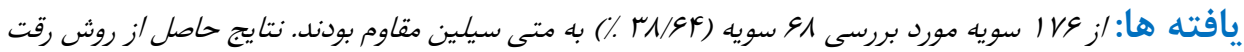

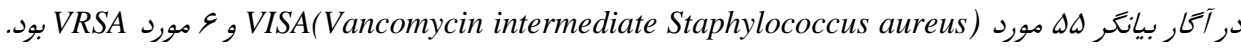

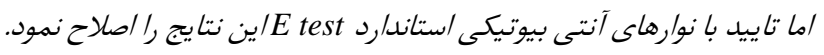
وصول:

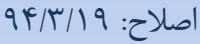
يذّيرش: نتيجه تيرى: بروز سويه هاى VISA و VRSA درمان عفونت ها را با محدوديت مواجه كرده است، بنابراين لازم

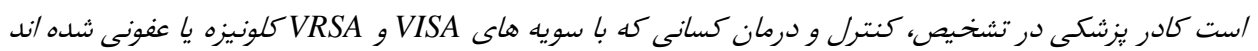
اهميت بيشترى قائل شوند. وازه هاى كليدى:MRSA, Etest, VRSA) 
ها، مانند كوليت كاذب ناشى از كلستريديوم ديفيسيل

و وفونت هاى ناشى از (Clostridium difficile) استافيلوكوكوس هاى كوآكولاز منفى (CoNS) در بيماران

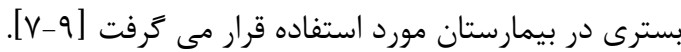
متاسفانه، افزايش روند استفاده از اين آنتى بيوتيك منجر

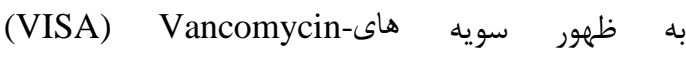
(VRSA) Vancomycin , intermediate S.aureus

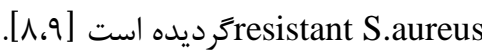
اولين ايزوله كلينيكى VISA در سال 199V در زاين

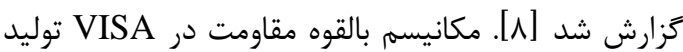
بيش از اندازه بيش ماده هاى ديواره سلولى است كه منجر

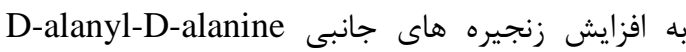

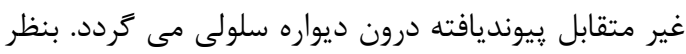
مى رسد اين باقى مانده هاى اضافى كليكويِتيدها را بـانه

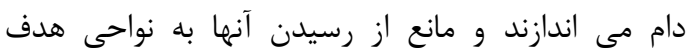
نزديك غشاى سيتويلاسمى مى شود.

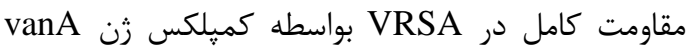
ميانجى گرى مى شود. vanA بر روى عنصر زنتيكى

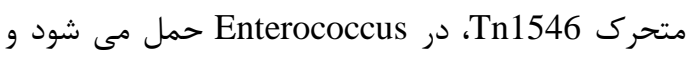
مى تواند بوسيله عمل transconjugation به يك سويه

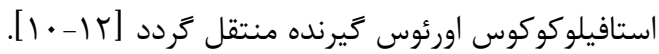

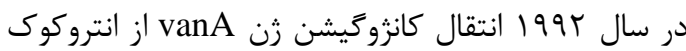
به استافيلوكوكوس اورئوس در محيط آزمايشعاه اثبات

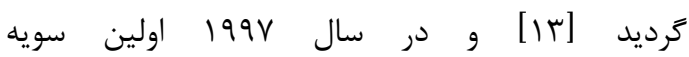
Vancomycin Intermediate )VISA

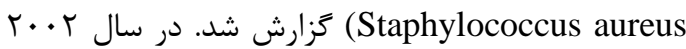
اولين ايزوله كلينيكى استافيلوكوكوس اورئوس با ميزان

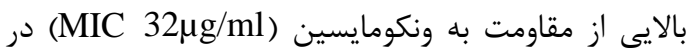

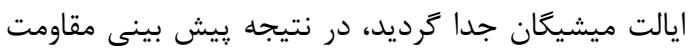

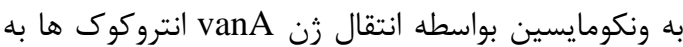
استافيلوكوكوس اورئوس به وقوع بِيوست و منجر به ظهور Vancomycin Resistance )VRSA (Staphylococcus aureus هاى مقاوم به ونكومايسين و مقاومت آنتى بيوتيكى آنها و

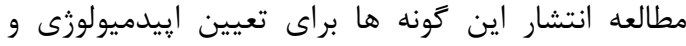

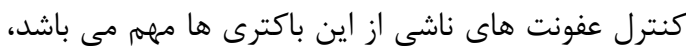

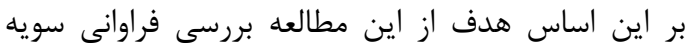

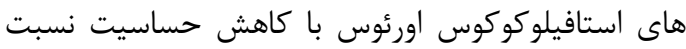

مقلهمه

استافيلوكوكوس اورئوس يك كوكسى گرم مثبت با فاكتورهاى ويرولانس بيشمارى است كه توانايى دستيابى

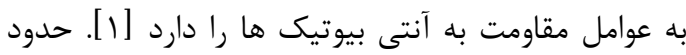

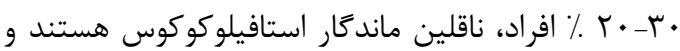

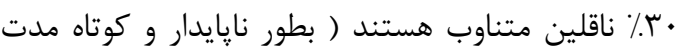

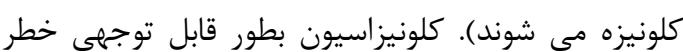

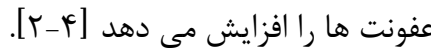
اين باكترى يكى از علل بسيار شايع عفونت هاى جرئ دهرئ

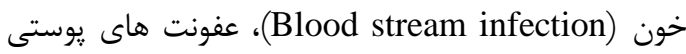
و زخم، استئوميليت، اندوكارديت، ينومونى و عفونت هاى

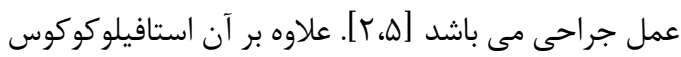

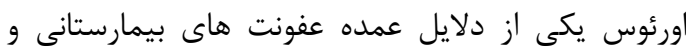

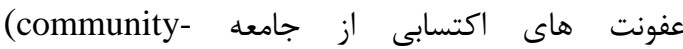
است كه مى تواند منجر به پيامدهاى جدى acquired) شود [r] اهميت اين پاتوزن انسانى، علاوه بر توانايى آن در ايجاد

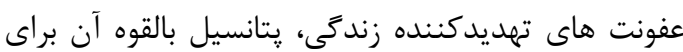

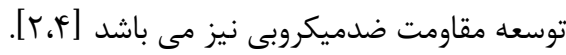

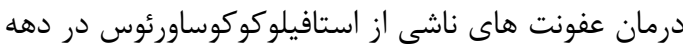
194.

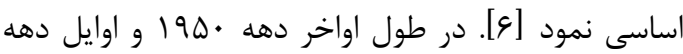

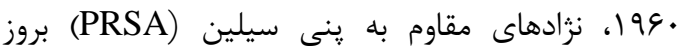

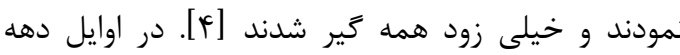

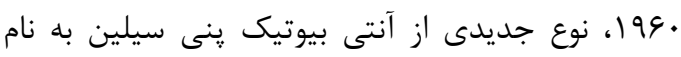

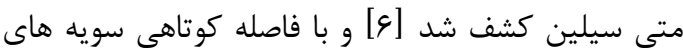
مقاوم به متى سيلين (MRSA) در سال 1991 دالئ در

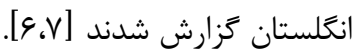
آنتى بيوتيك هاى كليكويتيتيد (ونكومايسين و تيكويلانين) بطور كسترده براى طب ييشكيرى و درمان عفونت هاى

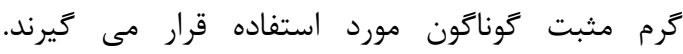
ونكومايسين، يس از تاييد بوسيله اداره كل غذا و دارو دارو در

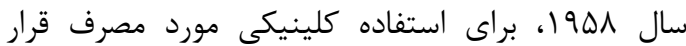
كرفت [ه]]. در كذشته، ونكومايسين بعنوان استانداردان طلايى براى درمان عفونت هاى جدى ايجاد شده بوسيله MRSA دارو، و همجنين بطور گسترده براى درمان ساير عفونت 
سويه هاى مقاوم به متى سيلين به روش ديسك ديفيوزن،

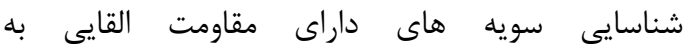

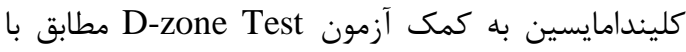
دستورالعمل سازمان استانداردهاى بالينى و آزمايشكاهى انجام شد. پِ از انجام روش ديسك ديفيوزن

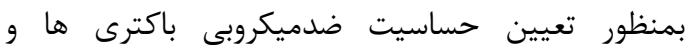
شناسايى سويه هاى MRSA، در مورد آنتى بيوتيك ونكومايسين، حداقل غلظت مهارى (MIC)، با كمك روش

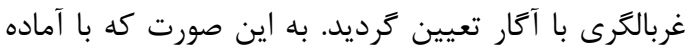

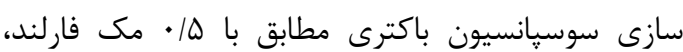

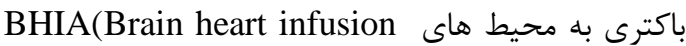
تاوى ونكومايسين ( agar)

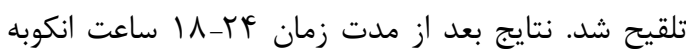
در ها درجه سانتى تراد بررسى و مطابق با استاندارد CLSI 19 ميكرو 19 هستند، در نتيجه توسط روش E test تاييد و MIC دقيق

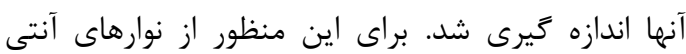

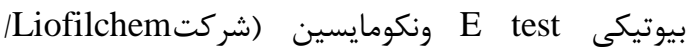
ايتاليا) استفاده گرديد. جهت تعيين MIC در ابتدا سوسيانسيونى از كشت تازه باكترى مورد نظر با كدورت

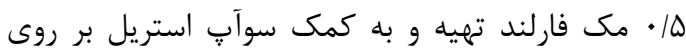
محيط مولر هينتون آكار كشت داده شد. پر إز از كذاشتن

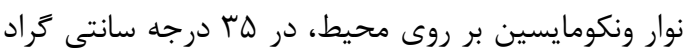

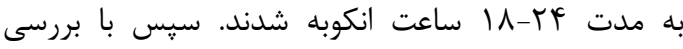

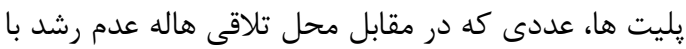

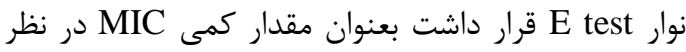
كرفته شد بر مبناى استانداردهاى CLSI براى ايزوله هاى داى

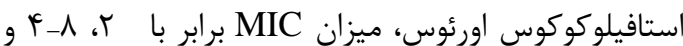

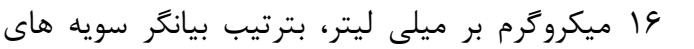

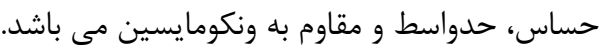

نافته ها در اين مطالعه در طى V ماه تعداد IVG سويه

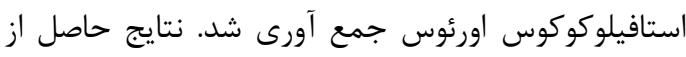

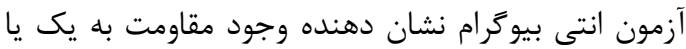
جندين آنتى بيوتيك در هر سويه بود (نمودار (،⿳) إ). از

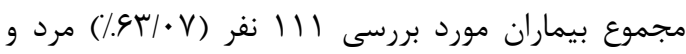

به ونكومايسين، جدا شده از نمونه هاى كلينيكى بيماران بسترى در بيمارستان هاى دانشكاهى امام رضا (ع) و قائم

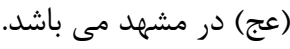

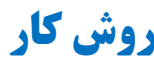

در اين مطالعه طى V ماه، از ارديبهشت تا آبان بوح، سويه

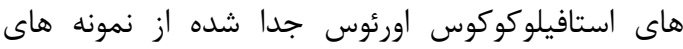
بالينى بيماران بسترى و سريايى، شامل خون، زخهم، ادرار،

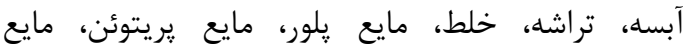

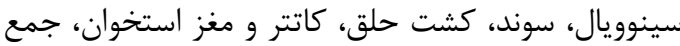

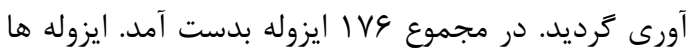

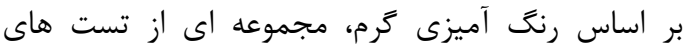

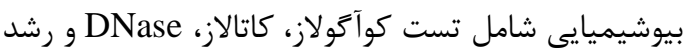

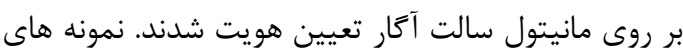
مورد تاييد سيس در دماى • V- درجه سانتى گراد تا انجام

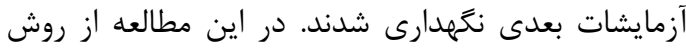

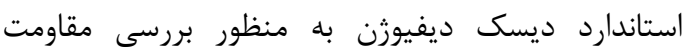
دارويى اوليه استفاده شد. ديسك هاى انتخابى شامل: ونكومايسين، كليندامايسين، اريترومايسين، جنتامايسين،

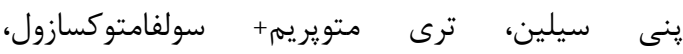
سفوكسيتين، نووبيوسين و باسيتراسين (محصول شركت (Rosco جزو ديسك هاى تشخيصى مى باشند كه به منظور تاييد نهايى سويه هاى استافيلوكوكوس اورئوس از استافيلوكوى

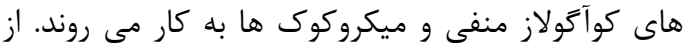

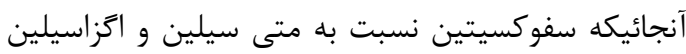
يايدارى و نتايج بهترى دارد، به منظور تعيين سويه هاى

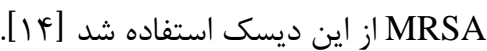
به منظور انجام تست، سوسيانسيون باكتريايى با غلظت

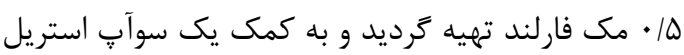
در روى محيط كشت مولر هينتون آكار كشت داده شد.

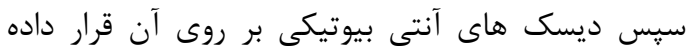

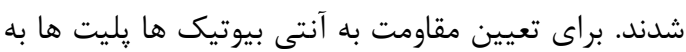

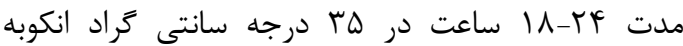

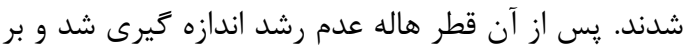
مبناى استانداردهاى Standard Institute )CLSI جlinical and Laboratory

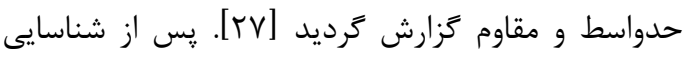




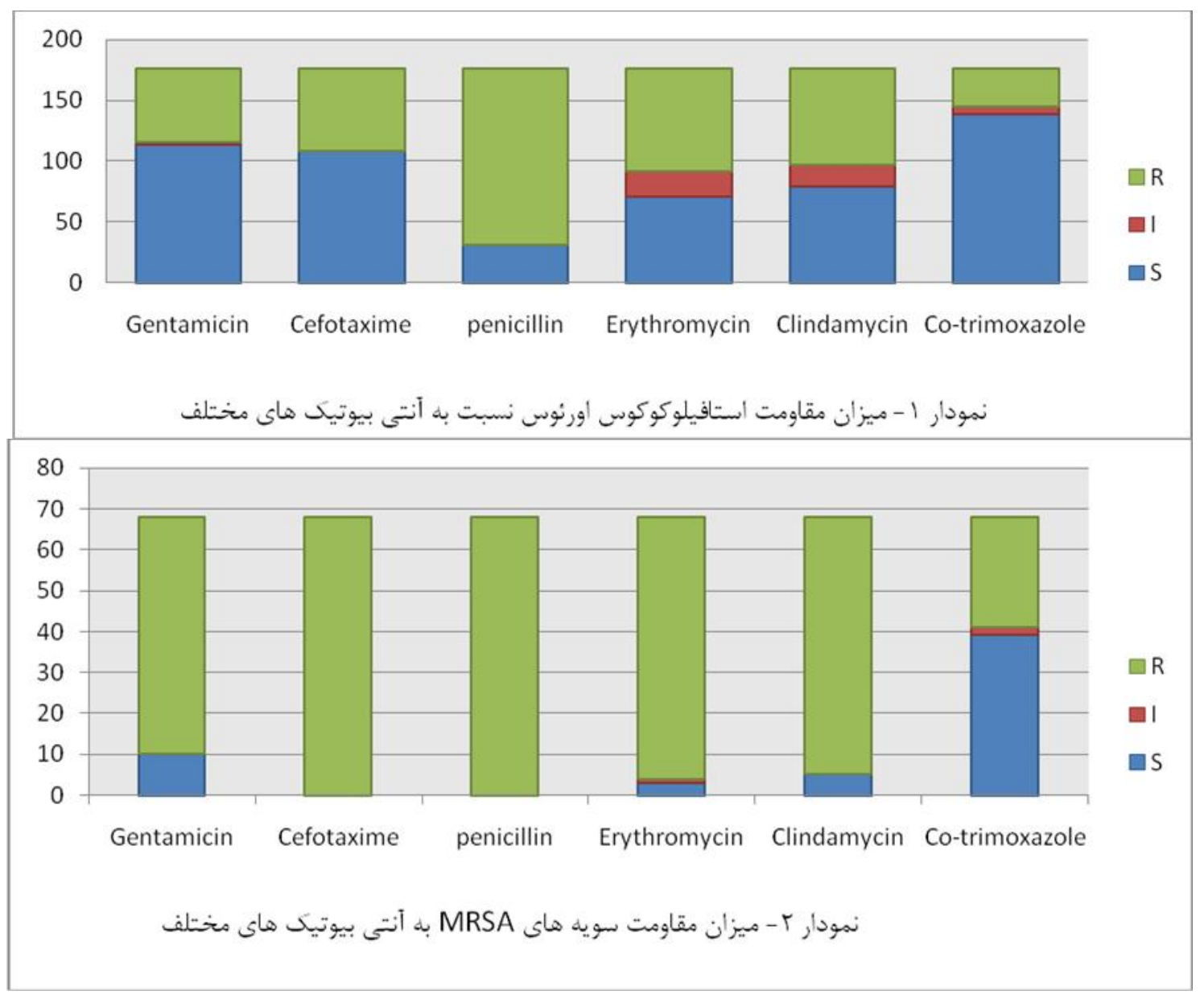

\begin{tabular}{|c|c|c|}
\hline (\%)MRSA & S.aureus & 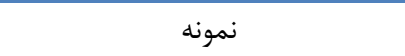 \\
\hline$\Delta(r \cdot)$ & TQ & ادرار \\
\hline $19(r / / V V)$ & $4 q$ & خون ان \\
\hline $1(1 \cdots)$ & 1 & $\mathrm{CSF}$ \\
\hline $\mathbb{R}(\Psi \varepsilon / \mid \Delta)$ & rq & زخم \\
\hline$V(\Delta r / \Lambda \Delta)$ & ir & تراشه \\
\hline$I V(\Delta r / \mid r)$ & rt & ت ت ترشحات \\
\hline V(Tr/T) & r. & ساير (برونش، كاتتر، درن، جشم و...) \\
\hline $9 \Lambda(\Psi N / G Y)$ & IVe & مجموع \\
\hline
\end{tabular}


جدول r: فراوانى ايزولههاى MRSA در بخشهاى مختلف

\begin{tabular}{|c|c|c|}
\hline MRSA (\%) & S.aureus & بخش \\
\hline $19(\Gamma \mid / \Gamma \Lambda)$ & QI & اورزانس ها \\
\hline$\pi(9 \Delta)$ & $r \cdot$ & آى سى يو ها \\
\hline$\wedge(\Delta \cdot)$ & 19 & داخلى \\
\hline$G(\Delta F / \Delta F)$ & 11 & جراحى \\
\hline$\Delta(\Delta \Delta / \Delta \Delta)$ & 9 & اطفال \\
\hline$r(99 \mid 99)$ & r & NICU \\
\hline I (זr & r & نفرولوزى \\
\hline $9(9 \cdot)$ & 1. & سوختگى \\
\hline $1(\Delta \cdot)$ & r & توراكس \\
\hline$\cdot(\cdot)$ & r & $\mathrm{CCU}$ \\
\hline$r(r \cdot)$ & $\Delta$ & يوست \\
\hline$r(r \cdot)$ & 1. & سوانح \\
\hline$\cdot(\cdot)$ & r & كوش- حلق- بينى \\
\hline $1(T \Delta)$ & r & عفونى \\
\hline$F(\mid Q / r \Lambda)$ & re & سريايى \\
\hline $9 \Lambda(T N / G Y)$ & IVE & مجموع \\
\hline
\end{tabular}

جدول rا: نتايج تست آتار اسكرين و E.test نمونهاى مشكوك به VRSA

\begin{tabular}{|c|c|c|c|c|}
\hline E.test & ريتيت رشد بر روى & ريت رشد بر روى & MRSA & شماره نمونه \\
\hline 1 & + & + & No & 1 \\
\hline$\cdot / 0$ & + & + & No & r \\
\hline .10 & + & + & No & r \\
\hline$\cdot 10$ & + & + & No & k \\
\hline$\cdot 10$ & + & + & Yes & $\Delta$ \\
\hline$\cdot / V \Delta$ & + & + & Yes & 9 \\
\hline
\end{tabular}


شادى ' و همكاران در مصر انجام كرديد از • • T نمونه

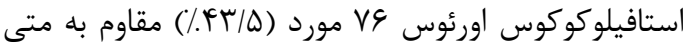

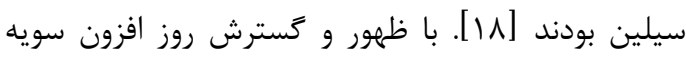

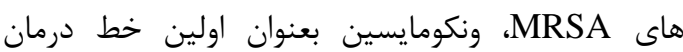
عفونت هاى ناشى از اين سويه ها مورد استفاده قرار كرفت إناين $[\Delta, v]$ با كزارش اولين VRSA در سال r +. r و كسترش آن در جهان، ما با مشكل درمان MRSA مواجه هستيم و بان

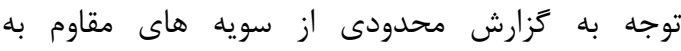

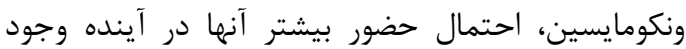
دارد [ه]]. در نقاط مختلف جهان مطالعاتى در مورد شيوع إنمان استافيلوكوك هاى مقاوم به ونكومايسين انجام شده است.

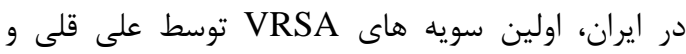

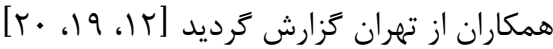
در اين مطالعه MIC به كمك روش رقت در آتار براى

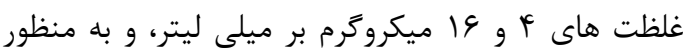

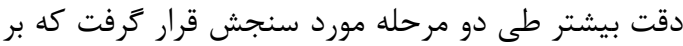

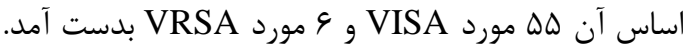

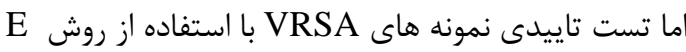

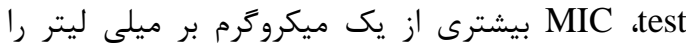

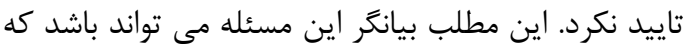

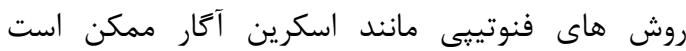
دستخوش خطاها و جهش هاى In-vitro قرار بكيرد، لذا بكاركيرى روش هاى فنوتييى استاندارد تر مانند استفاده

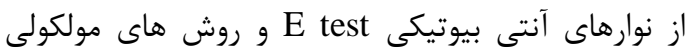
نظير PCR براى رديابى زن مقاومت بمنظور تاييد صد در صد سويه هاى VRSA لازم و ضرورى است.

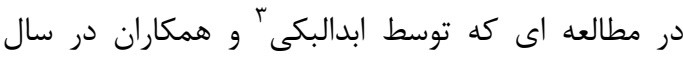

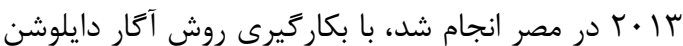

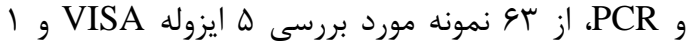

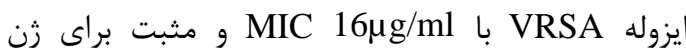

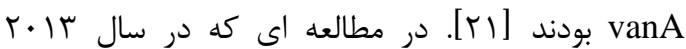

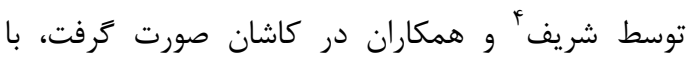

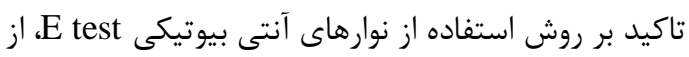

2-shady

3-Abd El-Baky

4-Sharif
9D نفر (سو/

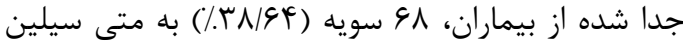
مقاوم بودند. بيشترين سويه هاى مقاوم از نمونه هاى

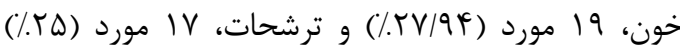

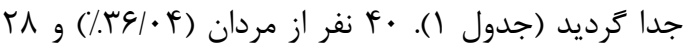

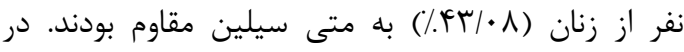

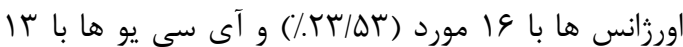

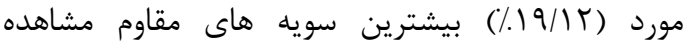
IV9 كرديد. بر اساس نتايج تست رقت در آتار از ميان

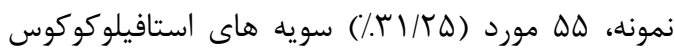
ورئوس با MIC داشتند. از مجموع فه مورد الب مورد

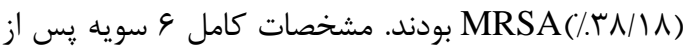
انجام E test در جدول ب گزارش شده است. نتايج تست

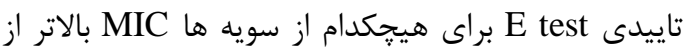

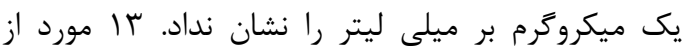

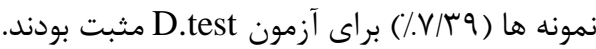
هجث

استافيلوكوكوس اورئوس يكى از شايعترين عوامل موثر در

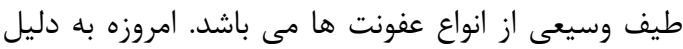

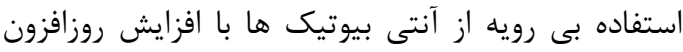
مقاومت آنتى بيوتيكى مواجه هستيه. در ايران نيز انتشار

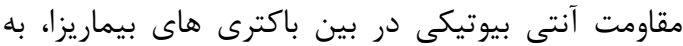

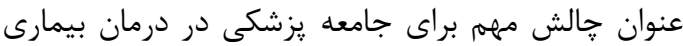

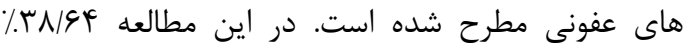
سويه ها بعنوان MRSA شناخته شدند. شيوع عفونت هاى ناشى از MRSA براى اولين بار در

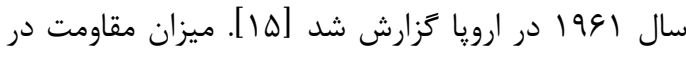

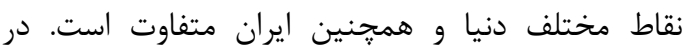

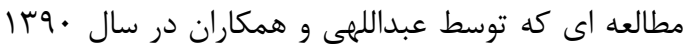

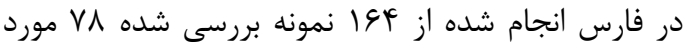
(

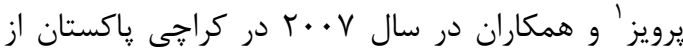

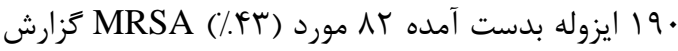

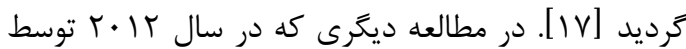

1-Perwaiz 


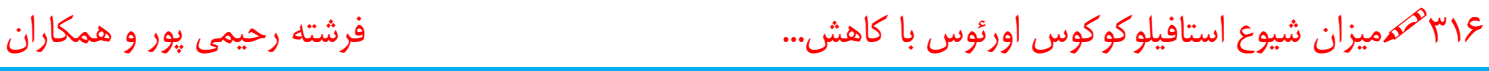

References

1. Tong SY, Chen LF, Fowler VG, Jr. Colonization, pathogenicity, host susceptibility and therapeutics for Staphylococcus aureus: what is the clinical relevance? 2012;34(2):185-200.

2. Plata K, Rosato AE, Weggrzyn G, Staphylococcus aureus as an infectious agent: overview of biochemistry and molecular genetics of its pathogenicity, Acta Biochimica Polonica, 2009;56(4):597612.

3. Liu GY, Molecular pathogenesis of Staphylococcus aureus infection, Pediatr Res. 2009;65(5 Pt 2):71R -R.

4. DeLeo FR, Otto M, Kreiswirth BN, Chambers HF, Community-associated meticillin-resistant Staphylococcus aureus, Lancet, 2010;375(9725):1557-68.

5. Tarai B, Das P, Kumar D, Recurrent Challenges for Clinicians: Emergence of Methicillin-Resistant Staphylococcus aureus, Vancomycin Resistance, and Current Treatment Options, J Lab Physicians, 2013;5(2):71-8.

6. Batabyal B, Kundu GKR, Biswas1 S, Methicillin-Resistant Staphylococcus aureus: A Brief Review, I Res J Biological Sci. 2012;1(7):65-71.

7. HowdenBP, Davies JK, Johnson PD, Stinear TP, Grayson ML, Reduced vancomycin susceptibility in Staphylococcus aureus, including vancomycin-intermediate and heterogeneous vancomycinintermediate strains: resistance mechanisms, laboratory detection, and clinical implications,ClinMicrobiolRev. 2010;23(1):99-139.

8. Appelbaum PC, The emergence of vancomycin-intermediate and vancomycin-resistant Staphylococcus aureus, Clin Microbiol Infect, 2006;12 Suppl 1(Suppl. 1):16-23.

9. Perichon B, Courvalin P, VanA-type vancomycin-resistant Staphylococcus aureus, Antimicrob Agents Chemother, 2009;53(11):4580-7.

10.Kobayashi SD, Musser JM, DeLeo FR, Genomic analysis of the emergence of vancomycinresistant Staphylococcusaureus, MBio. 2012;3(4).

11.Hiramatsu K, Kayayama Y ,Matsuo M, Aiba Y, Michie Saito, Hishinuma T, "et al", Vancomycinintermediate resistance in Staphylococcus aureus, Global Antimicrobial Resistance, 2014.

12.Azimian A, Havaei SA, Fazeli H, Naderi M, Ghazvini K, Samiee SM, "et al", Genetic Characterization of a Vancomycin-Resistant Staphylococcus aureus Isolate from the Respiratory Tract of a Patient in a University Hospital in Northeastern Iran, J Clin Microbiol, 2012;50(11):35815 [Persian]

13.Noble WC, Virani Z, Cree RG, Co-transfer of vancomycin and other resistance genes from Enterococcusfaecalis NCTC 12201 to Staphylococcus aureus, FEMS Microbiol Lett. 1992;72(2):1958.

14.Skov R, Smyth R, Clausen M, Larsen AR, Frimodt-Moller N, Olsson-Liljequist B," et al" ,Evaluation of a cefoxitin 30 microg disc on Iso-Sensitest agar for detection of methicillin-resistant Staphylococcusaureus, The Journal of antimicrobial chemotherapy, 2003;52(2):204-7.

15.Hasani A, Sheikhalizadeh V, Hasani A, Naghili B, Valizadeh V, Nikoonijad AR, Methicillin resistant and susceptible Staphylococcus aureus: Appraising therapeutic approaches in the Northwest of Iran, ijm. 2012;5(1):56-62[Persian]

16. Abdollahi A, Kouhpaye SA, Najafipour S, Mansouri Y, Abdollahi Kherabadi S, Jafari S, Frequency of drug resistance and staphylococcal chromosomal cassette mec (SCCmec).Genotype in Methicillin-Resistant Staphylococcus aureus strains.Behdad, Scientific and Research Journal of Alborz Medical Sciences, 2012, 1(1): 47-52[Persian]

17.Perwaiz S, Barakzi Q, Farooqi BJ, Khursheed N, Sabir N, Antimicrobial susceptibility pattern of clinical isolates of methicillin resistant Staphylococcus aureus, JPMA The Journal of the Pakistan Medical Association,2007;57(1):2-4

18.Abu Shady HM, El-Essawy AK, Salama MS, El-Ayesh AM, Detection and molecular characterization of vancomycin resistant Staphylococcus aureus from clinical isolates, African Journal of Biotechnology, 2012;11(99):16494-503. 


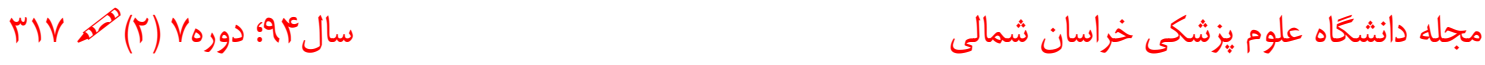

19.Aligholi M ,Emaneini M, Jabalameli F, Shahsavan S, Dabiri H, Sedaght H, Emergence of highlevel vancomycin-resistant Staphylococcus aureus in the Imam Khomeini Hospital in Tehran, Med Princ Pract. 2008;17(5):432-4.

20.Dezfulian A, Aslani MM, Oskoui M, Farrokh P, Azimirad M, Dabiri H, "et al", Identification and Characterization of a High Vancomycin-Resistant Staphylococcus aureus Harboring VanA Gene Cluster Isolated from Diabetic Foot Ulcer, Iranian Journal of Basic Medical Sciences, 2011;15(2):8036.

21.El-Baky RMA, Ahmed HR, Gad GFM, Prevalence and Conjugal Transfer of Vancomycin Resistance among Clinical Isolates of Staphylococcus aureus, Advances in Research, 2013;2(1):12-23. 22.Sharif MR, Alizargar J, Sharif A, Antibiotic Susceptibility of Staphylococcus aureus in Isolates of the Patients with Osteomyelitis, World Journal of Medical Sciences, 2013;9(3):180-3[Persian] 


\title{
Prevalence of staphylococcus aureus with reduced susceptibility against vancomycin in clinical samples isolate from Mashhad hospitalsduring 2014
}

\author{
Rahimipour $F^{1}$, Roudbari $F^{2}$, Azimian $A^{3}$, Youssefi $M^{4}$, Amel jamedar $S^{4}$, Ghazvini $K^{5}$
}

${ }^{1} \mathrm{MSc}$ in Microbiology, Department of Cell and Molecular Biology, Faculty of sciences

, University of Mazandran, Babolsar, Iran

${ }^{2}$ Assistant Professor ofMedicalVirology, Department of Cell and Molecular Biology,

Faculty of sciences, University of Mazandran, Babolsar, Iran

${ }^{3}$ Assistant Professor of Medical Bacteriology, Department of Pathobiology, School

of medicine, North Khorasan University of Medical Sciences, Bojnoord, Iran

${ }^{4}$ Assistant Professor of MedicalVirology, Antimicrobial resistance Research Center

, Buali Research Institute, Department of Microbiology and virology, School of medicine

, Mashhad University of Medical Sciences, Mashhad, Iran

${ }^{5}$ Assistant Professor of Medical Bacteriology, Antimicrobial resistance Research Center,

Buali Research Institute, Department of Microbiology and virology, School of medicine

, Mashhad University of Medical Sciences, Mashhad, Iran

Corresponding Author: Department of Microbiology and virology, School of medicine

, Mashhad University of Medical Sciences, Mashhad, Iran

Email: GhazviniK@ mums.ac.ir

\section{Abstract}

Background \& objectives:Staphylococcus aureus is one of the major causes of nosocomial infections. Recently, increase in its various drug-resistant strains, has increased health problems. Incidence of VRSA (vancomycin resistant Staphylococcus aureus) strains has created many concerns about the treatment of these bacterial infections. The aim of this study was to determine the frequency of Staphylococcus aureus with reduced susceptibility against vancomycinin clinical samples of patientsadmitted to the Ghaem and Imam Reza academic hospitals in Mashhad in 2014.

Material and methods:In this cross-sectional study within 7 months, 176 S.aureus isolates obtained from clinical samples and were identified using the biochemical methods. To determine the resistance, the disk diffusion method according to CLSI (Clinical and Laboratory Standards Institute) guidelines was used. The minimum inhibitory concentration (MIC) was evaluated by the agar dilution method and approved by E.test.

Results:Of 176 S.aureus isolates,68 strains (64/38\%) were methicillin resistant.The results of the agar dilution method represented 55cases of VISA (vancomycin intermediate Staphylococcus aureus) and 6 cases VRSA. But, these results confirm the correct with E.Test standard tapes.

Conclusion: Emergence of VISA and VRSA isolates has been limited treatment of infections. Therefore, clinicians must be aware of management of patients who are colonized or infected with VISA and VRSA

Keywords: MRSA, E.test, VRSA 